\title{
Purification of Indonesian Natural Graphite by Acid Leaching Method as Nuclear Fuel Matrix: Physical Characterization
}

\author{
Deni Mustika ${ }^{1}$, Torowati ${ }^{1}$, Sudirman ${ }^{2}$, Adel Fisli ${ }^{2}$, I M. Joni ${ }^{3}$, Ratih Langenati ${ }^{1}$, Jan Setiawan ${ }^{1}$ \\ ${ }^{1}$ Center for Nuclear Fuel Energy - National Nuclear Energy Agency (BATAN), Puspiptek Area, Setu, Tangerang Selatan, \\ Banten, 15314, Indonesia \\ ${ }^{2}$ Center for Science and Technology for advanced Material - National Nuclear Energy Agency (BATAN), Puspiptek \\ Area, Setu, Tangerang Selatan, Banten, 15314, Indonesia \\ ${ }^{3}$ Nanotechnology and Graphene Research Center (NGRC) Directorate of Research and Community Development, \\ Padjadjaran University, Jln. Raya Bandung-Sumedang Km. 21 Jatinangor, Sumedang Regency, West Java, 45363, \\ Indonesia \\ Correspondence: Deni Mustika, Center for Nuclear Fuel Energy - National Nuclear Energy Agency (BATAN), \\ Puspiptek Area, Setu, Tangerang Selatan, Banten, 15314, Indonesia. Tel: +62-85217039494. E-mail: \\ dmustika@batan.go.id
}

Received: December 14, 2018 Accepted: January 22, 2019 Online Published: January 31, 2019

doi:10.5539/ijc.v11n1p9

URL: https://doi.org/10.5539/ijc.v11n1p9

\begin{abstract}
Graphite matrix in Pebble Bed Reactor (PBR) fuel has an important role not only as neutron moderator and structural material to protect nuclear fuel, but also as heat transfer media. Therefore, the graphite matrix must meet the criteria of physical and chemical properties specified for PBR fuel. This paper focuses on the purification of the Indonesian natural graphite by using hydrometallurgy method with acid treatments. The characteristic of the purified graphite was studied for its specification compliance as a candidate of fuel matrix for PBR type of High Temperature Gas Cooled Reactor (HTGR). Acid and acid mixtures such as $\mathrm{HF}, \mathrm{HNO}_{3}+\mathrm{H}_{2} \mathrm{SO}_{4}$ and $\mathrm{HF}+\mathrm{HCl}+\mathrm{H}_{2} \mathrm{SO}_{4}$ were used for the purification process. Crystal structure examination by X-Ray Diffraction indicates that the graphite sample was $2 \mathrm{H}$ poly type with hexagonal crystal structure and lattice group of $\mathrm{P} 63 \mathrm{~m}$ c space group. It was observed that the graphite sample purified by $\mathrm{HNO}_{3}+\mathrm{H}_{2} \mathrm{SO}_{4}$ mixture had the closest resemblance to single crystalline graphite with a $\left\langle\mathrm{d}_{002}\right\rangle$ deviation of 0.94 when compared to perfect graphite crystal. The density of graphite decreases from $2.3273 \mathrm{~g} / \mathrm{cm}^{3}$ (before acid treatment) to 2.1808; 2.2203 and $2.2752 \mathrm{~g} / \mathrm{cm}^{3}$ after treatment with $\mathrm{HF}, \mathrm{HNO}_{3}+\mathrm{H}_{2} \mathrm{SO}_{4}$ and $\mathrm{HF}+\mathrm{HCl}+\mathrm{H}_{2} \mathrm{SO}_{4}$, respectively. These results are close to the theoretical density value of $2.26 \mathrm{~g} / \mathrm{cm}^{3}$. The surface area decreases from $10.346 \mathrm{~m}^{2} / \mathrm{g}$ to 6.177 ; 5.831 and $7.63 \mathrm{~m}^{2} / \mathrm{g}$ for the treated graphite with $\mathrm{HF}, \mathrm{HNO}_{3}+\mathrm{H}_{2} \mathrm{SO}_{4}$ and $\mathrm{HF}+\mathrm{HCl}+\mathrm{H}_{2} \mathrm{SO}_{4}$ respectively. However, these values are still higher than that of nuclear grade graphite (i.e. between 4.80 and $5.55 \mathrm{~m}^{2} / \mathrm{g}$ ). The average diameter size of graphite decreased from $29.65 \mu \mathrm{m}$ (before treated acid) into $23.12 \mu \mathrm{m}$ (after treated acid). The Indonesian natural graphite obtained from acid purification treatment is potential to be used as matrix material for PBR - HTGR fuel, but further treatment is necessary.
\end{abstract}

Keywords: nuclear fuel matrix, pebble bed reactor, htgr, indonesian natural graphite, acid purification, physical characterization

\section{Introduction}

Natural graphite occurs in methamorphic rock as a result of the reduction of sedimentary carbon compounds during metamorphism. It is found in nature in different types: lump or vein graphite, crystalline flake and amorphous (Jangbarwala; Marza et al.). Indonesia has a huge potential reserve of natural graphite in Sanggau Regency (West Kalimantan Province), Kolaka Regency (Southeast Sulawesi Province) and Lima Puluh Kota Regency (West Sumatera Province) with graphite percentage of 1,25 wt $\%$ to $65,56 \mathrm{wt} \%$ (Marza et al.; Sukandarrumidi).

With purification treatment, Indonesian natural graphite has the potential to be utilized as fuel matrix for Pebble Bed Reactor (PBR) type - High Temperature Gas Cooled Reactor (HTGR). The fuel element consists of a spherical fuel zone of $50 \mathrm{~mm}$ in diameter, in which the fissile material in the form of coated particle is embedded in a matrix of graphite material. The graphite matrix in PBR fuel serves not only as neutron moderator and structural material to protect nuclear fuel, but also as heat transfer media (Hongsheng Zhao et al.; IAEA, "High Temperature Gas Cooled Reactor 
Fuels and Materials"). Therefore, the graphite matrix for PBR fuel must meet the criteria of the specified physical and chemical properties such as high purity, low impurity and equivalent boron content, low ash content, high density, high thermal conductivity, high mechanical strength, good corrosion resistance and excellent irradiation performance (Hongsheng Zhao et al.; IAEA, "High Temperature Gas Cooled Reactor Fuels and Materials"; IAEA, "Advances in High Temperature Gas Cooled Reactor Fuel Technology"; Lyon). Demand of matrix material with high density emerges from the need not only for high mechanical strength of the fuel spheres as structural material but also for high thermal conductivity to maintain thermal gradient low. The limitation of graphitization temperature to $\left\langle 2000^{\circ} \mathrm{C}\right.$ is that it requires the use of highly crystalline graphite powder as raw material (IAEA, "Advances in High Temperature Gas Cooled Reactor Fuel Technology").

The composition of graphite matrix for PBR - HTGR, also known as A3 - 3 graphite matrix, is $64 \%$ natural graphite, $16 \%$ synthetic graphite and $20 \%$ phenolic resin (Tang et al.; IAEA, "High Temperature Gas Cooled Reactor Fuels and Materials"; X. Zhou et al.; Magampa et al.; IAEA, "Advances in High Temperature Gas Cooled Reactor Fuel Technology"; Yeo et al.). Natural graphite used in A3-3 graphite matrix must fulfill the physical and chemical criteria for nuclear grade graphite requirements such as low impurity content, equivalent boron content, surface area, particle size distribution, ash content and density. Graphite is a natural element consisting of carbon (C) with hexagonal crystal structure with a density of 2.23 to $2.266 \mathrm{~g} / \mathrm{cm}^{3}$ (Sukandarrumidi; Lyon). Yeo et al., Tang, et al. and Zhao et al. used natural graphite as HTGR nuclear fuel matrix with high purity $(>99 \%)$. The natural graphite characteristics with such purity had lithium content below $0.005 \mu \mathrm{g} / \mathrm{g}$, boron equivalent below $1 \mu \mathrm{g} / \mathrm{g}$, and ash content about $100 \mu \mathrm{g} / \mathrm{g}$. The specific surface area was within the range of 4.8 to $5.5 \mathrm{~m}^{2} / \mathrm{g}$. The particle size distribution of the graphite used by Yeo et al. and Tang et al. was $90 \%$ graphite within size range of $32-63 \mu \mathrm{m}$. Zhao, et.al used graphite with $100 \%$ graphite within particle size smaller than $80 \mu \mathrm{m}$ and $71.20 \%$ within particle size smaller than $25 \mu \mathrm{m}$. According to IAEA Tec Doc 1674, the recommended particle size for graphite is $50 \%$ within particle size smaller than $32 \mu \mathrm{m}$ (Yeo et al.; Tang et al.; Hongsheng Zhao et al.; IAEA, “Advances in High Temperature Gas Cooled Reactor Fuel Technology”).

To improve the beneficial quality of Indonesian natural graphite for PBR-HTGR matrix utilization, purification process should be done. Graphite purification has been extensively studied in recent years. In general, natural graphite purification process can be classified into hydrometallurgy process (acid base) and pyrometallurgy (heat treatment)(Xie et al.; Haipeng Zhao et al.; Zaghib et al.; Li et al.; KIM and KIM). Both methods are preceded by flotation method and some suitable reagents are usually added to increase the effectiveness of recovery (Florena et al.; Joni et al.). Flotation is a process of separation and concentration based on differences in the physicochemical properties of interfaces (Florena et al.). Tang et al. and Zhao et al. performed purification of Chinese natural graphite for nuclear application, especially for nuclear fuel matrix. In their work they used the mixture of $\mathrm{HF}, \mathrm{HCl}$ and $\mathrm{H}_{2} \mathrm{SO}_{4}$ for the purification process (Tang et al.; Hongsheng Zhao et al.). During the early stage of the purification process by flotation method, the carbon content can be increased to $69.73 \mathrm{wt} \%$ (Florena et al.; Syarifuddin et al.). Moreover, flotation method with Denver-like flotation cell DEX and pine oil addition with $\mathrm{pH}$ adjustment, the carbon content can be increased to $91 \mathrm{wt} \%$ (Joni et al.), while acid leaching with hydrofluoric acid applied to purify Indonesian natural graphite concentrate has further increased carbon content of the resulting graphite up to $98 \%$ (Panatarani et al.; Syarifuddin et al.).

This paper focuses on the purification of Indonesian natural graphite by hydrometallurgy method with acid variation. The acid used were fluoride acid, nitrite acid + sulfuric acid $\left(\mathrm{H}_{2} \mathrm{SO}_{4}+\mathrm{HNO}_{3}\right)$ and fluoride acid + chloride acid + sulfuric acid $\left(\mathrm{HF}+\mathrm{HCl}+\mathrm{H}_{2} \mathrm{SO}_{4}\right)$. Physical characterization was done to both the natural graphite before the purification process and the purified graphite to be utilized as a candidate for PBR - HTGR fuel matrix. The purpose of this research to reveal the preliminary physical characteristics of Indonesian natural graphite purified by acid variation.

\section{Method and Materials}

The natural graphite sample was from Sanggau District, West Kalimantan Province, Indonesia. The sample has been through milling and flotation process (Joni et al.). The chemical materials used in this study were fluoride acid (HF), sulfuric acid $\left(\mathrm{H}_{2} \mathrm{SO}_{4}\right)$, chloride acid $(\mathrm{HCl})$, and nitric acid $\left(\mathrm{HNO}_{3}\right)$. All of the chemicals used were pro-analysis products of Merck.

The method for purification was acid leaching with acid variation of $\mathrm{HF}, \mathrm{H}_{2} \mathrm{SO}_{4}+\mathrm{HNO}_{3}$ with $1: 1$ ratio and $\mathrm{HF}+\mathrm{HCl}+\mathrm{H}_{2} \mathrm{SO}_{4}$ with 1:1:1 ratio. Graphite and acid were mixtured for leaching at a 1:5 weight ratio. The mixtures were stirred for 3 hours and washed by aquadest for several times until free-acid graphite was obtained. The yielded free-acid graphite was dried at $115^{\circ} \mathrm{C}$ in an oven and subsequently crushed.

Examination of graphite crystal structure was performed with Panalytical Empyrean X-Ray Diffractometer with $\mathrm{Cu}-\mathrm{K} \alpha$ radiation source on 2 theta from $20^{\circ}$ to $80^{\circ}$. Highscore plus software from Panalytical and Crystallography Open Database (COD) were used to analyze the obtained X-Ray diffraction patterns. Density characterization was done with $\mathrm{He}$ - autopycnometer Ultrapyc 1200-e, Quantachrome by gas displacement and expansion method. Surface area of the 
resulted powder was analyzed by Brunauer - Emmett - Teller (BET) equation using Quantasorb SI, Quantachrome Instrument. The microstructure of the graphite was analyzed with Scanning Electron Microscopy (SEM) JEOL 6510LA. Particles size distribution was examined with Particles size analyzer PSA Micro Cilas 1190 liquid by Fraunhofer method.

\section{Result and Discussion}

This section describes the physical characteristics of the Indonesian natural graphite before and after purification process. The X-Ray diffraction pattern in 2 theta between 20-80 degree is presented in Figure 1.

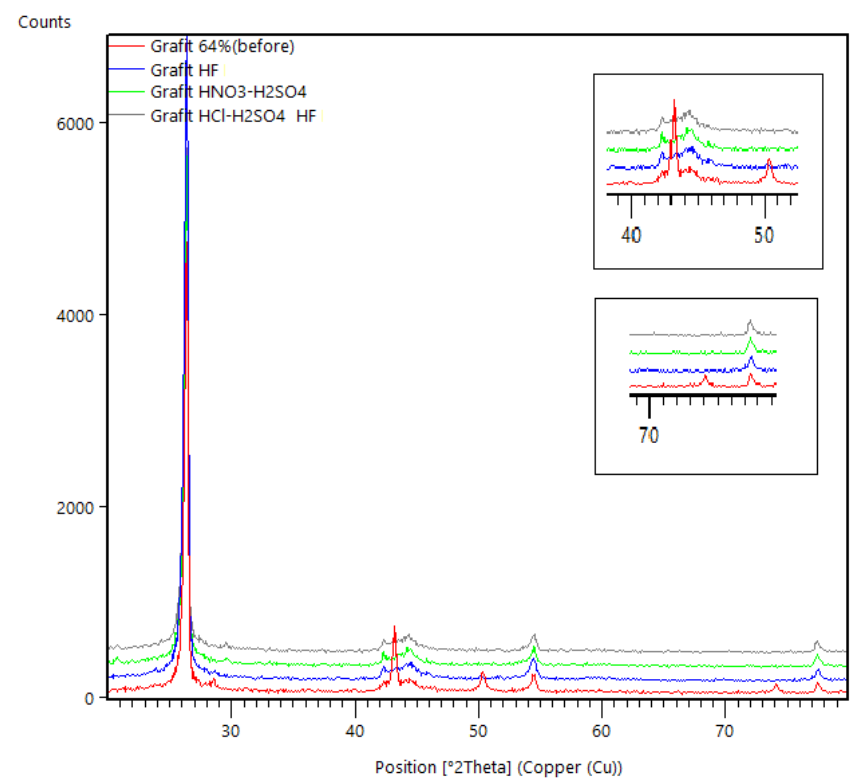

Figure 1. X-ray diffraction patterns of the Indonesian natural graphite before and after purification with acid variation

The diffraction pattern of graphite before purification process is labeled by Grafit $64 \%$ with observed peaks position at $26.249^{\circ}, 28.442^{\circ}, 42.29^{\circ}, 43.094^{\circ}, 44.33^{\circ}, 50.271^{\circ}, 54.303^{\circ}, 73.889^{\circ}$ and $77.32^{\circ}$. Meanwhile, the diffraction peaks for purified graphite by acid leaching was observed at $26.249^{\circ}, 42.29^{\circ}, 44.33^{\circ}, 50.271^{\circ}, 54.303^{\circ}$ and $77.32^{\circ}$. The phase analysis of natural graphite before and after purification shows a match with database card number of 96-120-0018 and 96-901-1578. Crystallography information of these cards is presented in Table 1.

Table 1. Crystallography information of graphite

\begin{tabular}{cccccl}
\hline \multicolumn{3}{c}{$96-120-0018$} & \multicolumn{2}{c}{$96-901-1578$} \\
\hline 2 theta & hkl & Space group: P 63 m c & 2 theta & hkl & Space group: P 63 m c \\
$26.228^{\circ}$ & {$[002]$} & & $26.543^{\circ}$ & {$[002]$} & \\
$42.214^{\circ}$ & {$[010]$} & Lattice parameters: & $42.321^{\circ}$ & {$[010]$} & Lattice parameters: \\
$44.365^{\circ}$ & {$[011]$} & a: $2.4700 \AA$ & $44.518^{\circ}$ & {$[011]$} & a: $2.4640 \AA$ \\
$50.381^{\circ}$ & {$[112]$} & c: $6.7900 \AA$ & $50.656^{\circ}$ & {$[112]$} & c: $6.7110 \AA$ \\
$53.974^{\circ}$ & {$[004]$} & & $54.662^{\circ}$ & {$[004]$} & \\
$59.404^{\circ}$ & {$[013]$} & Theoretical density: & $59.852^{\circ}$ & {$[013]$} & Theoretical density: \\
$70.804^{\circ}$ & {$[014]$} & 2.22 g/cm & $71.471^{\circ}$ & {$[014]$} & 2.26 g/cm \\
$77.177^{\circ}$ & {$[110]$} & RIR: 2.44 & $77.400^{\circ}$ & {$[110]$} & RIR: 2.31 \\
\hline
\end{tabular}

The residual peaks at 2 theta of $28.442^{\circ}, 43.094^{\circ}$ and $73.889^{\circ}$ are predicted as peaks of impurities, although they are not expected in purified graphite. The information from database card number of 96-120-0018 is used to analyze before and after graphite purification to obtain the real lattice parameter. Table 2 shows the lattice parameter of graphite before and after purification. 
Table 2. Crystal lattice parameter of the Indonesian natural graphite before and after purification

\begin{tabular}{ccc}
\hline Graphite & \multicolumn{2}{c}{ Crystal lattice parameter } \\
& $\mathrm{a}(\AA)$ & $\mathrm{c}(\AA)$ \\
\hline Before acid treatment & 2.467339 & 6.734424 \\
$\mathrm{HF}$ & 2.459424 & 6.743481 \\
$\mathrm{HNO}_{3}+\mathrm{H}_{2} \mathrm{SO}_{4}$ & 2.461565 & 6.735619 \\
$\mathrm{HF}+\mathrm{HCl}+\mathrm{H}_{2} \mathrm{SO}_{4}$ & 2.4622 & 6.74188
\end{tabular}

Table 2 shows the lattice parameter of the natural graphite before and after purification. The value of lattice parameter a before and after graphite purification varies from 2.4594 to $2.4673 \AA$. The a value deviates within a range of 0.023 to $0.256 \%$ from the single crystalline graphite reference, $2.461 \AA$ (Z. Zhou et al.). The purified Graphite purified with $\mathrm{HNO}_{3}+\mathrm{H}_{2} \mathrm{SO}_{4}$ has the closest value to single crystalline graphite. The $\mathrm{c}(\AA)$ value tends to decrease for the purification with acid ( $\left.\mathrm{HF}, \mathrm{HNO}_{3}+\mathrm{H}_{2} \mathrm{SO}_{4}, \mathrm{HF}+\mathrm{HCl}+\mathrm{H}_{2} \mathrm{SO}_{4}\right)$, while the lattice parameter a $(\AA)$ tends to increase. This phenomenon indicates that there is a change in crystal structure as a result of acid purification process. The graphite purified with $\mathrm{HF}$ has the most notable change in crystal structure when compared to those resulted from purification with other acid mixtures variation.

The analysis results of $\left\langle\mathrm{d}_{002}\right\rangle$ for before purification, after purification with $\mathrm{HF}, \mathrm{HNO}_{3}+\mathrm{H}_{2} \mathrm{SO}_{4}$ and $\mathrm{HF}+\mathrm{HCl}+\mathrm{H}_{2} \mathrm{SO}_{4}$ are $3.39227,3.38716,3.38553$ and $3.38736 \AA$ respectively. The deviation for those analysis results are 1.14, $0.98,0.94$ and 0.995 respectively. As comparison, the value for perfect graphite crystal is $3.354 \AA$ (Z. Zhou et al.; Zhou Zhou et al.; Barnakov et al.). The $\left\langle\mathrm{d}_{002}\right\rangle$ has commonly been used in measurement as degree of graphitization of carbon material. Graphite with $\left\langle\mathrm{d}_{002}\right\rangle$ much larger than that of perfect graphite crystal usually has turbostratic structure. The hexagonal layer of turbostratic forms two dimensional lattice with $\left\langle\mathrm{d}_{002}\right\rangle$ of $3.440 \AA$. The graphitization of graphite will increase if the deviation of $\left\langle\mathrm{d}_{002}\right\rangle$ is close to perfect crystal of graphite. The smaller the deviation value when compared to perfect crystal graphite, the more capable of the graphite to moderate neutrons (Iwashita; Krishna et al.; Wen et al.; Barnakov et al.; Zhou Zhou et al.; Z. Zhou et al.). Heat treatment of graphite in gradual manner could decrease the $\left\langle\mathrm{d}_{002}\right\rangle$ value because of the weak Vander Waals interaction of spacing between adjacent layers (Iwashita).

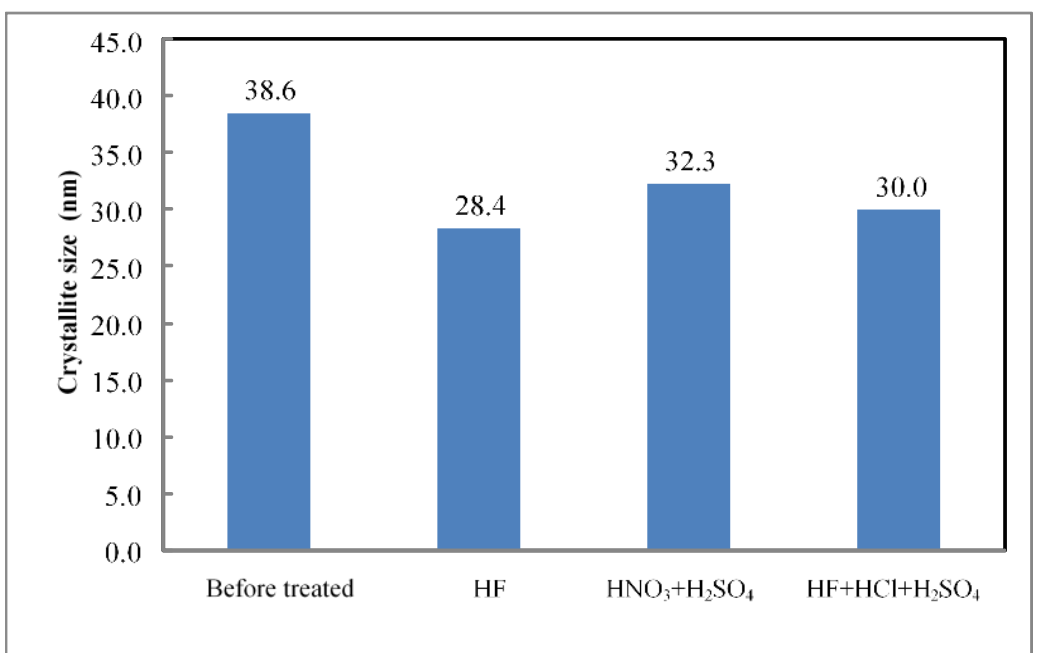

Figure 2. Crystallite size value of before and after treated acid of graphite

The crystallite size of graphite was calculated from the broadening major diffraction peak (002) plane using the Scherrer's formula;

$$
\text { Crytallite size }=\frac{0.9 \lambda}{B \cos \theta}
$$

Where $\lambda$ is the $X$-ray wavelength, $\theta$ is the angle of Bragg diffraction, and $B$ is the difference between the full-width at half-maximum (FWHM) of peak and the instrumental broadening correction. Figure 2 shows the crystallite size of graphite before and after acid treatment. The graphite has crystallite size of $38.6 \mathrm{~nm}$. After acid treatment the crystallite size of graphite decreases to $28.4 \mathrm{~nm}, 32.3 \mathrm{~nm}$ and $30.0 \mathrm{~nm}$ for treatment with $\mathrm{HF}, \mathrm{HNO}_{3}+\mathrm{H}_{2} \mathrm{SO}_{4}$ and $\mathrm{HF}+\mathrm{HCl}+\mathrm{H}_{2} \mathrm{SO}_{4}$ respectively. The crystallite size decreases after acid treatment of graphite. Increase in purity of the graphite as 
explained by XRD analysis above may be responsible for this observation.

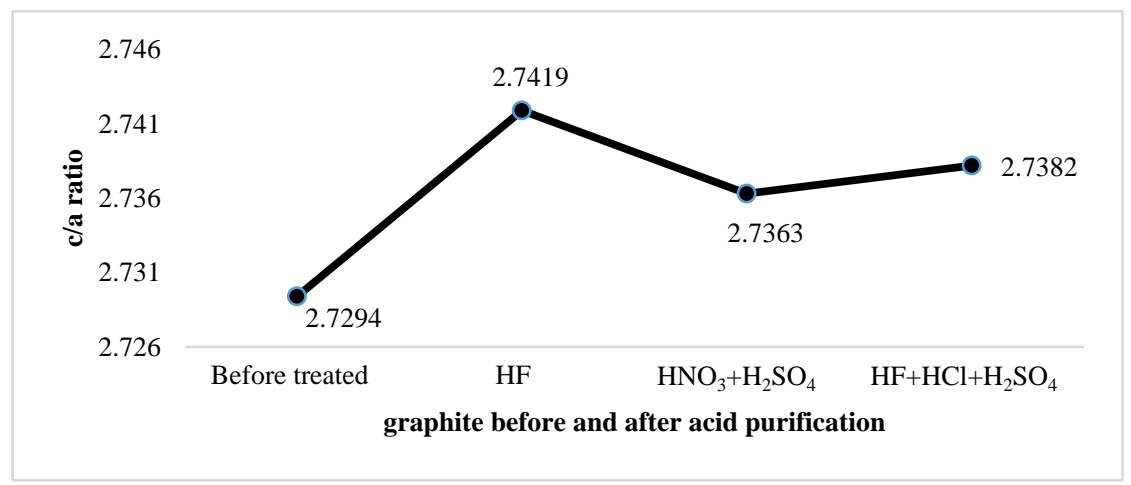

Figure 3. c/a ratio of Indonesian natural graphite before and after acid purification

Figure 3 shows the ratio of lattice parameter $\mathrm{c}$ to lattice parameter a (c/a ratio) of Indonesian natural graphite before and after acid purification with $\mathrm{HNO}_{3}+\mathrm{H}_{2} \mathrm{SO}_{4}$ and $\mathrm{HF}+\mathrm{HCl}+\mathrm{H}_{2} \mathrm{SO}_{4}$, the value of which are 2.7294, 2.7419, 2.7363 and 2.7382 respectively. The c/a ratio obtained is in the range of the card number 96-120-0018 and 96-901-1578, 2.7236 and 2.74898 respectively.

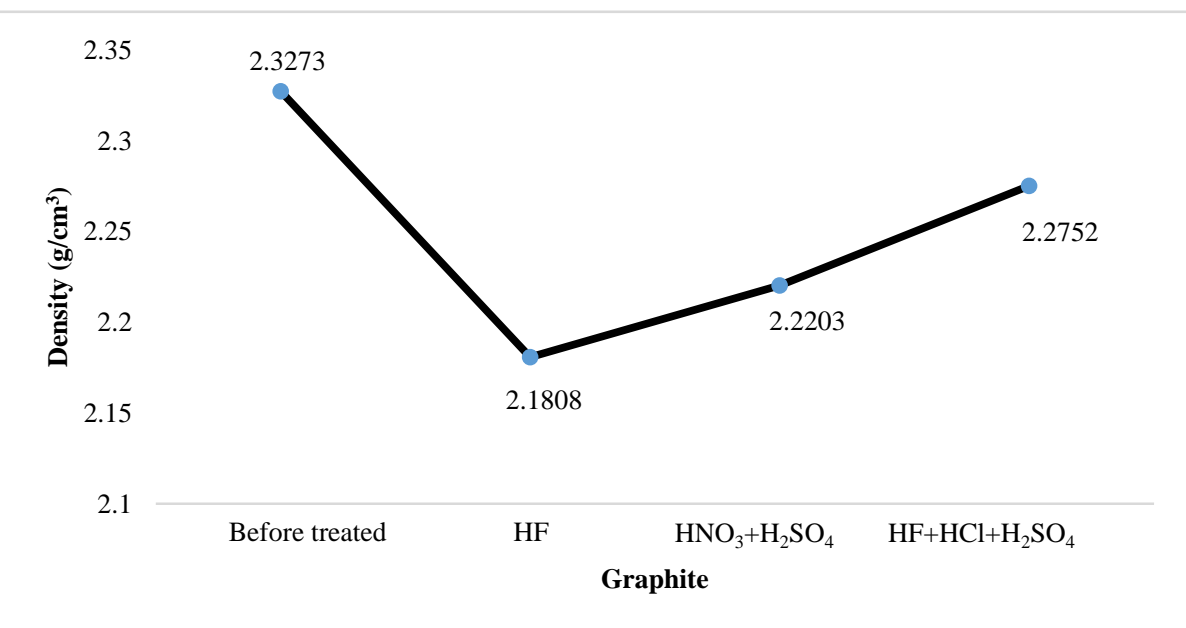

Figure 4. Density of Indonesian natural graphite before and after acid purification

The density of Indonesian natural graphite before and after acid purification is shown in Figure 4. The density of graphite before purification is $2.3273 \mathrm{~g} / \mathrm{cm}^{3}$. The density of graphite after purification with $\mathrm{HF}, \mathrm{HNO}_{3}+\mathrm{H}_{2} \mathrm{SO}_{4}$ and $\mathrm{HF}+\mathrm{HCl}+\mathrm{H}_{2} \mathrm{SO}_{4}$ changes into $2.1808,2.2203$ and $2.2752 \mathrm{~g} / \mathrm{cm}^{3}$ respectively. In general, the density of purified graphite is lower than the density of graphite before purification process. The decreasing of density may occur due to increase in grade of purity as a result of purification process. Purified graphite using HF has the lowest density below its theoretical density. This phenomenon can be caused by the exfoliation of graphite which causes an increase in the volume of graphite (Panatarani et al.). The lowest density of natural graphite purified with HF is in good agreement with its highest c/a ratio in Figure 3. The higher density of natural graphite before purification compared to theoretical density $\left(2.22 \mathrm{~g} / \mathrm{cm}^{3}\right.$ and $2.26 \mathrm{~g} / \mathrm{cm}^{3}$ ) can be caused by impurities content in graphite. The highest possible density of free-impurities natural graphite indicates high quality of graphite, which is needed for high mechanical strength of the fuel spheres as structural material and for excellent thermal conductivity.

Figure 5 shows the SEM image of natural graphite before and after acid purification. The graphite before purification shows some agglomeration with random position at the surface, while the purified graphite shows less agglomeration. The acid of $\mathrm{HF}$ and $\mathrm{HF}+\mathrm{HCl}+\mathrm{H}_{2} \mathrm{SO}_{4}$ used for purification resulted in smoother graphite surface than acid mixture of $\mathrm{HNO}_{3}+\mathrm{H}_{2} \mathrm{SO}_{4}$ and before purification. SEM image shows the diameter of graphite before and after purification varies within the range of 1 to $100 \mu \mathrm{m}$. It can be seen in the figure that there are many small size particles on the graphite surface before purification. The amount of small size particles decreases for the graphite after purification. 

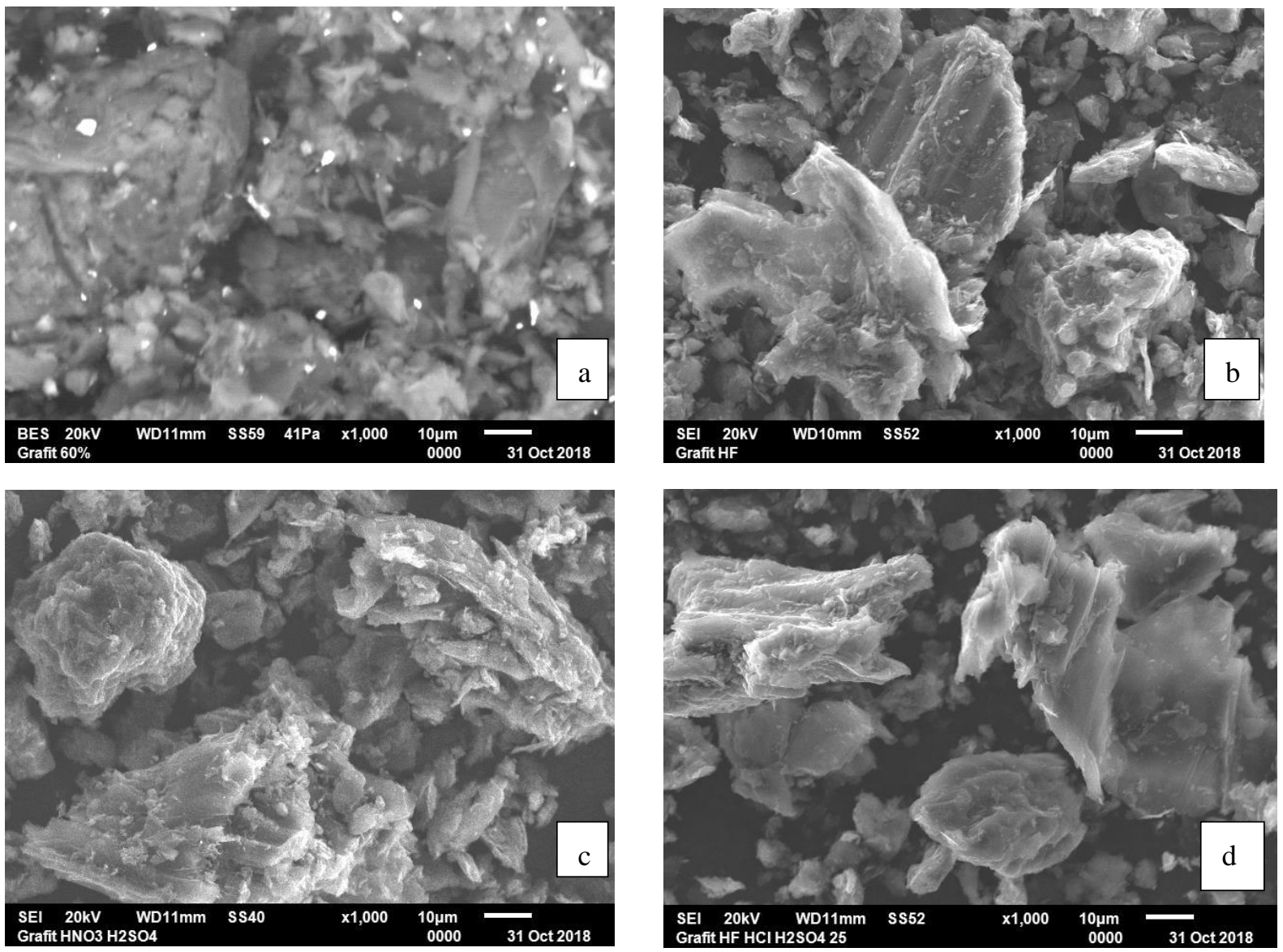

Figure 5. Graphite SEM Image a. before purification b. after purification using HF c. Purified using $\mathrm{HNO}_{3}+\mathrm{H}_{2} \mathrm{SO}_{4}$ d.

Purified using $\mathrm{HF}+\mathrm{HCl}+\mathrm{H}_{2} \mathrm{SO}_{4}$

The surface area of the Indonesian natural graphite before and after acid purification is shown in Figure 6. The surface area of graphite before purification is $10.346 \mathrm{~m}^{2} / \mathrm{g}$. The surface area of graphite after purification with $\mathrm{HF}$, $\mathrm{HNO}_{3}+\mathrm{H}_{2} \mathrm{SO}_{4}$, and $\mathrm{HF}+\mathrm{HCl}+\mathrm{H}_{2} \mathrm{SO}_{4}$ changes into $6.177,5.831$ and $7.63 \mathrm{~m}^{2} / \mathrm{g}$ respectively. These results indicates that the surface area of the Indonesian natural graphite decreases after purification. It decrease due to the lost of impurities particles in the structure graphite. The presence of agglomeration of impurities particles can contribute to the increase in surface area of graphite, which corresponds to Figure 5a. The surface area of nuclear graphite were observed to be varied within the range of $4.8 \mathrm{~m}^{2} / \mathrm{g}$ to $5.55 \mathrm{~m}^{2} / \mathrm{g}$ (Yeo et al.; Hongsheng Zhao et al.). However, the surface area values obtained are still higher than those observed by Yeo et al.(2018) and Hongsheng Zhao et al. (2006). The surface area of graphite bears a relation to corrosion properties of graphite and can also be used to determine the corrosion type (IAEA, "Advances in High Temperature Gas Cooled Reactor Fuel Technology").

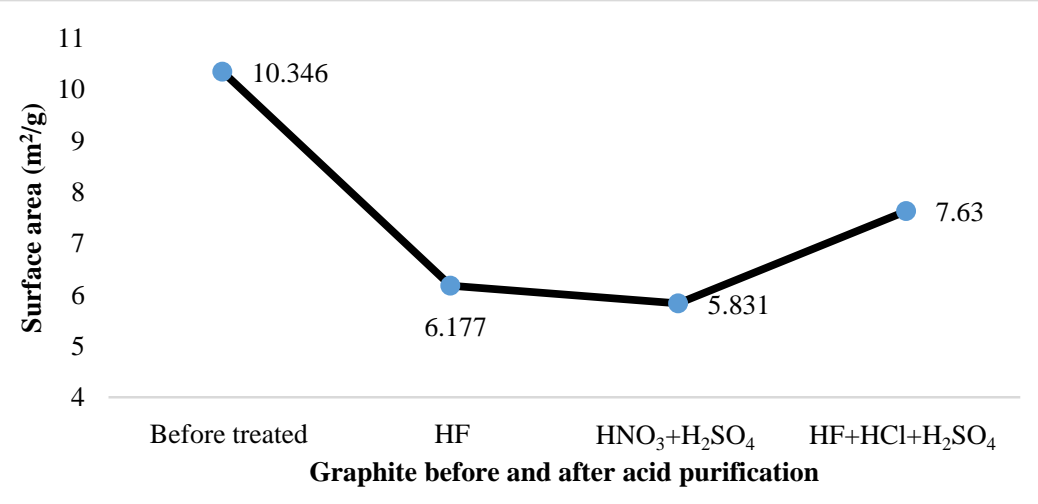

Figure 6. Surface area of Indonesian natural graphite before and after acid purification 


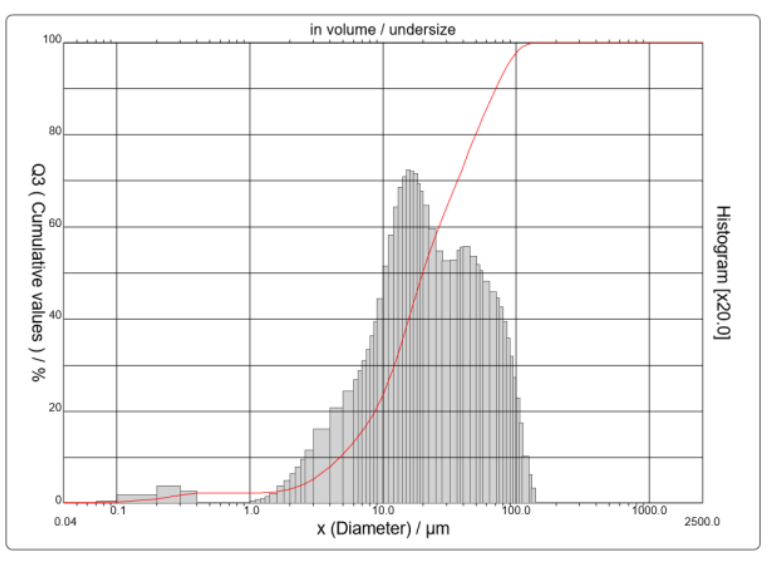

$\mathrm{a}$

$\begin{array}{lll}\text { Diameter at } 10 \% & : 4.74 & \mu \mathrm{m} \\ \text { Diameter at } 50 \% & : 19.87 & \mu \mathrm{m} \\ \text { Diameter at } 90 \% & : 70.32 & \mu \mathrm{m} \\ \text { Mean diameter } & : 29.65 & \mu \mathrm{m}\end{array}$

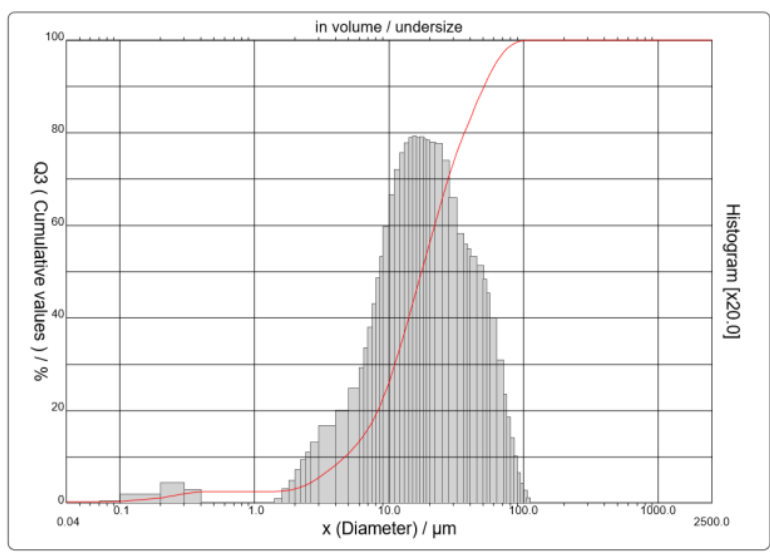

b

$\begin{array}{lll}\text { Diameter at } 10 \% & : 4.66 & \mu \mathrm{m} \\ \text { Diameter at } 50 \% & : 17.47 & \mu \mathrm{m} \\ \text { Diameter at } 90 \% & : 50.81 & \mu \mathrm{m} \\ \text { Mean diameter } & : 23.12 & \mu \mathrm{m}\end{array}$

Figure 7. Particle size distribution Indonesian natural graphite a. Before purification b. After $\mathrm{HNO}_{3}+\mathrm{H}_{2} \mathrm{SO}_{4}$ purification Figure 7 shows particle size distribution of the Indonesian natural graphite before and after acid purification. It is observed that particle size average decreases from $29.65 \mu \mathrm{m}$ (before purification) to $23.12 \mu \mathrm{m}$ (after purification). The change in particle diameter is likely due to the decreasing of impurity content at the particle surface. Because of this phenomenon, the average diameter of the particles becomes smaller. Referring to Yeo et al., Tang et al., Zhao, et al. the diameter of graphite before and after acid purification still does not meet the requirements of nuclear grade graphite. However, according to IAEA TecDoc number 1674, the recommended graphite particle diameter at 50\% smaller than 32 $\mu \mathrm{m}$. The IAEA recommendation could be met by graphite before and after acid purification with diameter at $50 \%$ of 19.87 and $17.47 \mu \mathrm{m}$.

\section{Conclusion}

Physical characterization of the Indonesian natural graphite before and after purification was carried out to study its potential as candidate for nuclear fuel matrix for PBR - HTGR. The observed graphite has the characteristics of $2 \mathrm{H}$ poly type, hexagonal crystal structure and $\mathrm{P} 63 \mathrm{~m}$ c space group. The lattice parameters of graphite changed during acid purification. The graphite purified with $\mathrm{HNO}_{3}+\mathrm{H}_{2} \mathrm{SO}_{4}$ has the closest value to single crystal graphite with a deviation of $\left\langle\mathrm{d}_{002}\right\rangle$ at 0.94 when compared to perfect graphite crystal. It is observed that the density of graphite after $\mathrm{HNO}_{3}+\mathrm{H}_{2} \mathrm{SO}_{4}$ and $\mathrm{HF}+\mathrm{HCl}+\mathrm{H}_{2} \mathrm{SO}_{4}$ differs but insignificantly from the theoretical density. The purified graphite has smoother surface than graphite before purification, and hence the surface area of graphite after acid purification is lower than that of graphite before purification. The surface area of graphite before and after purification are still higher than nuclear grade graphite. The IAEA recommendation for particle size distribution could be met by graphite before and after acid purification. From the physical density and particle size distribution point of view, the Indonesian natural graphite obtained from acid purification can be used as nuclear fuel matrix for PBR - HTGR, but the graphitization degree needs to be increased and the surface area needs to be decreased.

\section{Acknowledgment}

We would like to thank Ministry of Research, Technology and Higher Education (Indonesia) for funding this research through Insinas Flagship Program. We would also like to thank Dr. Geni Rina Sunaryo, M.Sc, Ir. Agus Sumaryanto, M.S.M and Prof. Ridwan for the provision of facilities to accomplish the research. We are also grateful to our colleagues from Padjadjaran University, Center for Nuclear Fuel Energy - National Nuclear Energy Agency (BATAN), Center for Science and Technology for advanced Material - National Nuclear Energy Agency (BATAN) for the assistance during the research.

\section{References}

Barnakov, Ch N., et al. (2015). XRD Characterization of the Structure of Graphites and Carbon Materials Obtained by the Low-Temperature Graphitization of Coal Tar Pitch XRD Characterization of the Structure of Graphites and Carbon Materials Obtained by the Low-Temperature Graphitization. Eurasion Chemico-Technological Journal, 17, no. March, 87-93. https://doi.org/10.18321/ectj198 
Florena, F. F., et al. (2016). Floatability Study of Graphite Ore from Southeast Sulawesi (Indonesia). AIP Conference Proceedings, 1712. https://doi.org/10.1063/1.4941888

IAEA. Advances in High Temperature Gas Cooled Reactor Fuel Technology. IAEA TECDOC CD 1674, 2012, 1-690.

IAEA. (2010). High Temperature Gas Cooled Reactor Fuels and Materials. IAEA Tecdoc 1645, 1-182.

Iwashita, N. (2016). Chapter 2 - X-Ray Powder Diffraction. Materials Science and Engineering of Carbon, Tsinghua University Press Limited., https://doi.org/10.1016/B978-0-12-805256-3.00002-7

Jangbarwala, J. M. (2017). Review of Carbonaceous Nanomaterials and Graphite. Graphitic Nano Fibers, Elsevier, 1340. https://doi.org/10.1016/B978-0-323-51104-9.00002-9

Joni, I. M., et al. (2013). Synthesis and Dispersion of Nanoparticles, and Indonesian Graphite Processing. AIP Conference Proceedings, 1554, 20-26. https://doi.org/10.1063/1.4820275

Kim, J. Y., \& Kim, B. (2007). Chemical and Low-Expansion Treatments for Purifying Natural Graphite Powder. Physicochemical Problems of Mineral Processing, 41, 37-49.

Krishna, R., et al. (2017). An Understanding of Lattice Strain , Defects and Disorder. Carbon, Elsevier B.V., https://doi.org/10.1016/j.carbon.2017.08.070

Li, Y. F., et al. (2012). Selectivity Heating Effect of Microwave on Purifying of Natural Graphite. Applied Mechanics and Materials, 174-177, 810-815. https://doi.org/10.4028/www.scientific.net/AMM.174-177.810

Lyon, S. B. (2010). Degradation of Carbon and Graphite. Corrosion and Degradation of Engineering Material, 3, Elsevier, 2271-2281.

Magampa, P. P., et al. (2013). Properties of Graphite Composites Based on Natural and Synthetic Graphite Powders and a Phenolic Novolac Binder. Journal of Nuclear Materials, 436(1-3), 76-83, https://doi.org/10.1016/j.jnucmat.2013.01.315

Marza, R., et al. (2018). The Mineral Graphite Prospects on the Borneo and Sulawesi Islands Proceedinf of Annual Activities of Center for Mineral Resources, Coal and Geothermal Fiscal Year 2017. vol. Book 2 : B, 219-29.

Panatarani, C., et al. (2016). Preparation of Graphite Oxide by Sodium Cholate Intercalation and Sonication from Indonesian Natural Graphite. AIP Conference Proceedings, 1712, no. March 2016, https://doi.org/10.1063/1.4941908

Sukandarrumidi. (2017). Minerals Industry Relating to Malihan Stone in Industrial Minerals, Gadjah Mada University Press, 223-224.

Syarifuddin, F., et al. (2016). Effect of Acid Leaching on Upgrading the Graphite Concentrate from West Kalimantan ( Indonesia ). AIP Conference Proceedings 1712, 050022. https://doi.org/10.1063/1.4941905

Tang, Chunhe, et al. (2002). Design and Manufacture of the Fuel Element for the $10 \mathrm{MW}$ High Temperature Gas-Cooled Reactor. Nuclear Engineering and Design, 218(1-3), 91-102. https://doi.org/10.1016/S0029-5493(02)00201-7

Wen, K. Y., et al. (2008). The Microstructure of Nuclear Graphite Binders. Carbon, 46(1), 62-71. https://doi.org/10.1016/j.carbon.2007.10.025

Xie, W, et al. (2016). Fixed Carbon Content and Reaction Mechanism of Natural Microcrystalline Graphite Purified by Hydrochloric Acid and Sodium Fluoride. International Journal of Mineral Processing, 155, Elsevier B.V., 45-54. https://doi.org/10.1016/j.minpro.2016.08.002

Yeo, S., et al. (2018). Fabrication Methods and Anisotropic Properties of Graphite Matrix Compacts for Use in HTGR. Journal of Nuclear Materials, 499, Elsevier B.V., 383-393, https://doi.org/10.1016/j.jnucmat.2017.11.055

Zaghib, K., et al. (2003). Purification Process of Natural Graphite as Anode for Li-Ion Batteries: Chemical versus Thermal. Journal of Power Sources, 119-121, 8-15, https://doi.org/10.1016/S0378-7753(03)00116-2

Zhao, H. P., et al. (2007). Purification and Carbon-Film-Coating of Natural Graphite as Anode Materials for Li-Ion Batteries. Electrochimica Acta, 52(19), 6006-6011, https://doi.org/10.1016/j.electacta.2007.03.050

Zhao, H. S., et al. (2006). Manufacture and Characteristics of Spherical Fuel Elements for the HTR-10. Nuclear Engineering and Design, 236(5-6), 643-647. https://doi.org/10.1016/j.nucengdes.2005.10.023

Zhou, X. W., et al. (2018). Study on the Comprehensive Properties and Microstructures of A3-3 Matrix Graphite Related to the High Temperature Purification Treatment. Hindawi Science and Technology of Nuclear Installation,.

Zhou, Z., et al. (2014). Interpretation of X-Ray Diffraction Patterns of (Nuclear) Graphite. Carbon, 69, Elsevier Ltd, 
17-24. https://doi.org/10.1016/j.carbon.2013.11.032

Zhou, Z., et al. (2017). Why Graphite? A Structural Study from the Atomic to the Macrocsopic. E-Journal of Advanced Maintenance, 9(2), 138-144.

\section{Copyrights}

Copyright for this article is retained by the author(s), with first publication rights granted to the journal.

This is an open-access article distributed under the terms and conditions of the Creative Commons Attribution license (http://creativecommons.org/licenses/by/4.0/). 